\title{
Thrombosis as the First Manifestation of Granulomatosis with Polyangiitis Disease in an Adolescent
}

\author{
Mohsen Jari \\ Department of Pediatric Rheumatology, Imam Hossein Children's Hospital, Isfahan University of Medical Sciences, Isfahan, Iran \\ Correspondence should be addressed to Mohsen Jari; mjari14@yahoo.com
}

Received 14 January 2021; Revised 22 February 2021; Accepted 28 February 2021; Published 3 March 2021

Academic Editor: Yusuke Shiozawa

Copyright $\odot 2021$ Mohsen Jari. This is an open access article distributed under the Creative Commons Attribution License, which permits unrestricted use, distribution, and reproduction in any medium, provided the original work is properly cited.

Background. Granulomatosis with polyangiitis disease (GPA) is a rare vasculitis characterized by granulomatous inflammation of respiratory tracts, glomerulonephritis, and vasculitis of other organs. Case Presentation. A 13-year-old girl was referred due to swelling and pain on her left arm. The Doppler and compression ultrasonography showed noncompressible left brachial and axillary vein thrombosis. Sinus computed tomography (CT) demonstrated pansinusitis, and spiral chest CT showed alveolar hemorrhage. Laboratory tests showed hematuria, proteinuria, and highly positive antineutrophil cytoplasmic antibody (cANCA). Laboratory tests of coagulopathy were normal. The patient was recognized as a case of GPA. Conclusion. Although GPA is not frequently associated with thrombosis especially in children, this is the first report that shows thrombosis may be the first manifestation of GPA in an adolescent.

\section{Introduction}

Thrombosis can occur in the artery or vein. Venous thrombosis is less common in children than in adults, but leads to more morbidity and mortality that emphasize timely diagnosis and therapy $[1,2]$. Risk factors for thrombosis include central venous catheter (CVC), immobility, heart disease, coagulation disorders, congenital heart disease, trauma (especially fractures), cancer, surgery, infections, dehydration, shock, obesity, nephrotic syndrome, antiphospholipid antibody syndrome, and vasculitis [1-3]. Granulomatosis with polyangiitis disease (GPA), formerly Wegener's granulomatosis, is a chronic vasculitis. Thrombosis is a rare manifestation of this disease especially in children and adolescents [2, 3].

\section{Case Presentation}

A 13-year-old girl was admitted to the pediatric rheumatology ward of Imam Hossein Children's Hospital, Isfahan University of Medical Sciences, due to swelling and pain on her left arm 3 days prior to admission. Since 3 months, she had fatigue, bloody nasal discharge, and cough.
On physical examination, she was alert, and her blood pressure and temperature were within normal limit. Her body weight was $43 \mathrm{~kg}$. There were no abnormalities on heart and lung examination. There was no lymphadenopathy or hepatosplenomegaly. There was swelling on her left arm without any sign of inflammation. The size of her left vs. right arm and left vs. right forearm was $28 \mathrm{~cm}$ vs. $23 \mathrm{~cm}$ and $18 \mathrm{~cm}$ vs. $17 \mathrm{~cm}$, respectively.

The radial and brachial pulses on the left were reduced. The laboratory examinations showed anemia (hemoglobin, $8.3 \mathrm{~g} / \mathrm{dL}$ ); leukocytosis (white blood count, $19500 / \mathrm{mm}^{3}$ (lymphocytes 24\%)); thrombocytosis (platelets $=530.000 /$ $\left.\mathrm{mm}^{3}\right)$; elevation of estimated sedimentation rate $(\mathrm{ESR}=105 \mathrm{~mm} / \mathrm{hr})$ and C-reactive protein $(\mathrm{CRP}=97 \mathrm{mg} / \mathrm{L})$; prothrombin time (PT), 13.0 seconds; INR, 1.1; activated partial thromboplastin time (aPTT), 32.3 seconds; and d-dimer $5.8 \mathrm{mg} / \mathrm{L}$ (normal $<0.3 \mathrm{mg} / \mathrm{L}$ ). The serum levels of protein $\mathrm{C}$, protein $\mathrm{S}$, antithrombin III, and factor V Leiden were normal. Renal function and electrolytes were within normal limits. Peripheral blood smear was normal.

Urinalysis showed proteinuria $3+$ and hematuria $4+$, and 24-hour urine showed proteinuria $(750 \mathrm{mg} / 24 \mathrm{hrs})$. Antinuclear antibody (ANA) was negative, and antiphospholipid 
antibodies, anti-DNA antibody, and serum complement levels were normal. Antineutrophil cytoplasmic antibody (ANCA) was highly positive (cANCA $=450 \mathrm{U} / \mathrm{ml}, \mathrm{Nl}<25 \mathrm{U} /$ $\mathrm{ml})$.

The Doppler and compression ultrasonography showed noncompressible and completely occlusive thrombosis of left brachial and axillary veins (noncompressible venous segment, lack of flow augmentation with calf squeeze, and increased flow in superficial veins). Sinus computed tomography (CT) demonstrated mucosal thickening and pansinusitis, and spiral chest CT showed minimal alveolar hemorrhage.

According to the EULAR/PRINTO//PRES criteria, the patient was recognized as a case of GPA, and the treatment started by prescribing subcutaneous enoxaparin and pulse methylprednisolone $30 \mathrm{mg} / \mathrm{kg} / \mathrm{d}$ ( $\max 1 \mathrm{gr}$ ) for three days. Then, in the fourth day of treatment, intravenous infusion (IV) with cyclophosphamide $500 \mathrm{mg} / \mathrm{m}^{2}$ was given. The patient was discharged in the fifth day given oral prednisolone $2 \mathrm{mg} / \mathrm{kg} / \mathrm{d}$ and enoxaparin. After a one-week followup, the Doppler and compression ultrasonography of left brachial and axillary veins was normal. Enoxaparin was continued (for three months), and IV cyclophosphamide, oral prednisolone, and azathioprine were continued based on EULAR/PRINTO//PRES criteria.

\section{Discussion}

Granulomatosis with polyangiitis disease (GPA) is not frequently associated with thrombosis. There are few reports of intracranial thrombosis of large and small vessels in adults and children. These events have been occurred due to intracranial vasculitis or extension of granulomatous lesions from the nasal cavity $[1,2]$. Few recent reports of thrombosis at other organs have been described in some adults, that are very rare in children and adolescents [3-6]. Systematic studies of factors contributing to hypercoagulability in these patients were not reported.

GPA is a antineutrophil cytoplasmic antibody- (ANCA-) associated vasculitis (AAV) characterized by necrotizing inflammation of small vessels and the presence of ANCA directed to specific antigens, particularly proteinase 3 (PR3ANCA) and myeloperoxidase (MPO-ANCA). This disease [7] primarily affects the small vessels of the skin, lungs, and kidneys. During AAV, proinflammatory cytokines are elevated in the serum of these patients.

Circulating tumor necrosis factor (TNF) is a major factor of atherothrombotic events in AAV $[8,9]$.

Pathogenesis of thrombosis in AAV including endothelial cell dysfunction and interaction between neutrophils (activated by TNF $\alpha$ and ANCA) and with consequent massive oxidative stress finally lead to atherothrombotic complications [10]. TNF can increase gene expression of procoagulant proteins, such as tissue factor. Anti-PR3 antibodies can increase the expression of tissue factor [11]. Recently, reports demonstrated that neutrophils are able to release extracellular nucleic acids associated with histones and granular proteins capable of entrapping bacterial agents $[12,13]$.
These mechanisms may explain why in patients with GPA thrombosis occurred during the initial stage of disease or when inflammation was not yet controlled.

\section{Conclusion}

Although GPA and other AAV are not frequently associated with thrombosis especially in children and adolescents, thrombosis may be the first manifestation of GPA.

\section{Data Availability}

The data used to support the findings of this study are available from the author upon request.

\section{Consent}

Written informed consent form has been provided by the parents to have the case details published.

\section{Conflicts of Interest}

The author declares no conflicts of interest.

\section{References}

[1] C. X. Tang, U. J. Schoepf, S. M. Chowdhury, M. A. Fox, L. J. Zhang, and G. M. Lu, "Multidetector computed tomography pulmonary angiography in childhood acute pulmonary embolism," Pediatric Radiology, vol. 45, no. 10, p. 1431, 2015.

[2] A. N. C. Santana, A. M. Ab'Saber, W. R. Teodoro, V. L. Capelozzi, and C. S. V. Barbas, "Trombose em artérias pulmonares pequenas e médias em granulomatose de Wegener: um estudo com microscopia confocal por varredura a laser," Jornal Brasileiro de Pneumologia, vol. 36, no. 6, pp. 724-730, 2010.

[3] P. Lamprecht, K. Holl-Ulrich, and S. Wieczorek, "Venous thromboembolism in Wegener's granulomatosis," The Journal of Rheumatology, vol. 34, no. 12, pp. 2323-2325, 2007.

[4] M. Mortazavi and H. Nasri, "Granulomatosis with polyangiitis (Wegener's) presenting as the right ventricular masses: a case report and review of the literature," Journal of Nephropathology, vol. 1, no. 1, 2012.

[5] J. C. Jennette, R. J. Falk, P. A. Bacon et al., "2012 revised international chapel hill consensus conference nomenclature of vasculitides," Arthritis \& Rheumatism, vol. 65, no. 1, pp. 1-11, 2013.

[6] M. F. Meyer, A. Schnabel, H. Schatz, and W. L. Gross, "Lack of association between antiphospholipid antibodies and thrombocytopenia in patients with Wegener's granulomatosis," Seminars in Arthritis and Rheumatism, vol. 31, no. 1, pp. 4-11, 2001.

[7] C. G. M. Kallenberg, "Key advances in the clinical approach to ANCA-associated vasculitis," Nature Reviews Rheumatology, vol. 10, no. 8, pp. 484-493, 2014.

[8] J. C. Jennette, R. J. Falk, P. Hu, and H. Xiao, "Pathogenesis of antineutrophil cytoplasmic autoantibody-associated smallvessel vasculitis," Annual Review of Pathology: Mechanisms of Disease, vol. 8, no. 1, pp. 139-160, 2013.

[9] D. P. Thomas and H. R. Roberts, "Hypercoagulability in venous and arterial thrombosis," Annals of Internal Medicine, vol. 126, no. 8, pp. 638-644, 1997. 
[10] I. L. Noronha, C. Krüger, K. Andrassy, E. Ritz, and R. Waldherr, "In situ production of TNF- $\alpha$, IL- $1 \beta$ and IL-2R in ANCA-positive glomerulonephritis," Kidney International, vol. 43, no. 3, pp. 682-692, 1993.

[11] M. De Bandt, V. Ollivier, C. Babin-Chevaye et al., "Induction of interleukin-1 and subsequent tissue factor expression by anti-proteinase 3 antibodies in human umbilical vein endothelial cells," Arthritis \& Rheumatism, vol. 40, no. 11, pp. 2030-2038, 1997.

[12] K. Kambas, A. Chrysanthopoulou, D. Vassilopoulos et al., "Tissue factor expression in neutrophil extracellular traps and neutrophil derived microparticles in antineutrophil cytoplasmic antibody associated vasculitis may promote thromboinflammation and the thrombophilic state associated with the disease," Annals of the Rheumatic Diseases, vol. 73, no. 10, pp. 1854-1863, 2014.

[13] S. Sangaletti, C. Tripodo, C. Chiodoni et al., "Neutrophil extracellular traps mediate transfer of cytoplasmic neutrophil antigens to myeloid dendritic cells toward ANCA induction and associated autoimmunity," Blood, vol. 120, no. 15, pp. 3007-3018, 2012. 